\title{
How Much Shared Decision Making Occurs in Usual Primary Care of Depression?
}

\author{
Leif I. Solberg, MD, A. Lauren Crain, PhD, Lisa Rubenstein, MD, \\ Jürgen Unützer, MD, MPH, Robin R. Whitebird, PhD, MSW, and Arne Beck, PhD
}

Background: Shared decision making (SDM) is an important component of patient-centered care, but there is little information about its use in the primary care of depression, so we sought to study its frequency in usual care as reported by patients.

Methods: Telephone interview of 1168 depressed patients taking antidepressants in 88 Minnesota primary care clinics who were identified from pharmacy claims data soon after a prescription for an antidepressant. We measured depression severity with the 9-item Patient Health Questionnaire and used a composite measure of SDM that reflected patient involvement in treatment decisions.

Results: These patients reported an average score for SDM of 50.7 (standard deviation, 32.8) on a scale of 0 to 100, where higher scores equate with greater SDM. In univariate analyses, the largest differences among scores were for age (scores of 58, 53, 45, and 33 for those aged 18-34, 35-49, 5064 , and $>64$ years, respectively; $P<.0001$ ); duration of treatment (a score of 56.6 on treatment $<6$ weeks vs 45.5 if longer; $P<.001)$; and other treatments in the past 6 months $(60.5$ if yes vs. 46.0 if no; $P=.001)$. SDM was not associated with any clinic characteristics, but it was correlated with patientreported quality of care $(r=0.48 ; P<.001)$. Multivariate analyses confirmed some of these findings while showing a more complex set of relationships.

Conclusions: Older patients with depression and those who have been in treatment longer report much less SDM in their care. Improving SDM, especially for these groups, may be an important target for improving patient experience and perceived quality. (J Am Board Fam Med 2014;27:199-208.)

Keywords: Decision Making, Depression, Patient-Centered Care, Patient Satisfaction, Primary Health Care

The Institute of Medicine report on quality of care in the United States in 2001 identified patientcenteredness as 1 of the 6 aims for "A new health system for the 21 st century." ${ }^{\text {Similarly, the current }}$ main vehicle for the primary care redesign that is widely seen as critical to that new health system is

This article was externally peer reviewed.

Submitted 21 May 2013; revised 5 November 2013; accepted 11 November 2013.

From the HealthPartners Institute for Education and Research, Minneapolis, MN (LIS, ALC, RRW); the RAND Corporation, Santa Monica, CA (LR); the Department of Psychiatry and Behavioral Sciences, University of Washington, Seattle (JU); and Kaiser Permanante Colorado, Denver (AB).

Funding: This research was funded by grant no. 5R01MH080692 from the National Institute of Mental Health.

Conflict of interest: none declared.

Corresponding author: Leif I. Solberg, MD, HealthPartners Institute for Education and Research, 8170 33rd Ave S, Bloomington, MN 55425 (E-mail: Leif.I.Solberg@ HealthPartners.com). the patient-centered medical home. ${ }^{2,3}$ The problem for either improvement efforts or any study of patient-centeredness is the lack of a commonly accepted definition or measurement. The most authoritative description is from the Institute of Medicine: "providing care that is respectful of and responsive to individual patient preferences, needs, and values and ensuring that patient values guide all clinical decisions." ${ }^{1}$ This suggests that the most important aspect of the complicated concept of patient-centeredness is the extent to which there is shared decision making (SDM). The Informed Medical Decision Foundation has defined SDM as "a collaborative process that allows patients and their providers to make health care decisions together, taking into account the best scientific evidence available, as well as the patient's values and preferences." 4 Barry and Edgman-Levitan ${ }^{4}$ call SDM "the pinnacle of patient-centered care," and Lin and Dudley ${ }^{5}$ suggest that the best measuring 
stick of patient-centeredness is that patients have adequate knowledge of the choices to be made and that treatment decisions reflect both patient desires for involvement and patient preferences/values (ie, SDM).

If improving patient-centeredness (and SDM) in primary care is such an important national goal, we first need to know how frequently current care reflects that goal. Unfortunately, there is no widely accepted measure of SDM. Kryworuchko et $\mathrm{al}^{6}$ performed a systematic review of primary outcome measures used in trials of patient decision support and found that the 35 trials used 35 different primary outcome measures. Whatever definition and measure are used, however, SDM has not been found to be a frequent part of usual medical practice. $^{7-9}$

It may be particularly important to understand and improve the frequency of SDM for patients with depression who are seen in primary care. Although common in primary care, patients who receive depression treatment in this setting often do not receive the same quality of care that has been shown to be possible in effectiveness studies of depression treatment. ${ }^{10-12}$ One of the key factors involved in effective care involves decision making related to available treatment options such as antidepressant medications or psychotherapy. Clever et $\mathrm{al}^{13}$ have demonstrated that both guideline-concordant care and remission rates are strongly associated with patient ratings of involvement in medical decision making. A randomized trial by Loh et $\mathrm{al}^{14}$ demonstrated that an intervention in German primary care with SDM training for physicians in and provision of a patient-centered decision aid led to greater doctor facilitation of patient participation, greater patient-rated involvement in care, and greater patient adherence. However, the only study of the frequency of SDM in usual care of depression is that of Young et $\mathrm{al},{ }^{15}$ who analyzed audiotapes of single interactions between physicians and standardized patients. They found that primary care physicians performed few SDM behaviors, but their study involved only standardized patient visits for new episodes of depression, did not address any patient or clinic factors, and did not incorporate the patient's perspective or report.

The specific aim of this study was to fill in those gaps by learning (1) how frequently patients report that specific SDM activities occur in real-life primary care of patients with depression and (2) what patient and clinic characteristics predict those activities. Our hypothesis was that both types of characteristics would demonstrate considerable variation, which we hoped could later be used to improve SDM. We took advantage of a Minnesota statewide initiative to improve primary care of depression in which patients reported on the care they had received in relation to patient and clinic characteristics. The reports of care by depressed patients were obtained before the implementation of any changes in care related to the initiative. ${ }^{16}$

\section{Methods}

The initiative that identified the clinics used in this study is called DIAMOND, Depression Improvement Across Minnesota-Offering a New Direction. ${ }^{16,17}$ The DIAMOND initiative involves a new monthly payment for enrolled patients from each of the private payers in the state for those primary care clinics that have been trained and certified to provide evidence-based collaborative care. ${ }^{18}$ Eighty-eight clinics volunteered to participate in this initiative in response to an announcement of the opportunity from the regional quality improvement collaborative. They were assigned to training as an implementation team for 6 months before they introduced the new system of care to their clinics. The initiative and training did not specifically address SDM, but to ensure that this report would describe usual care, we limited the analysis to patient survey data collected before any implementation of care changes.

\section{Subjects}

Subjects for this study were recruited from claims data provided by the 6 main health plans in the state and the Minnesota Department of Human Services on a weekly basis during the recruitment from February 2008 through September 2010. These data identified all adult patients from participating clinics with a fill for an antidepressant medication. Patients were excluded if they were on a research refusal list, were younger than 18 years old, lacked continuous insurance coverage for the previous 4 months, had received any antidepressant in those 4 months, or had already been identified for this study. Payers mailed a letter to potentially eligible patients describing the study and offering them the option of refusing to participate. Identifying information for those who did not opt out was sent weekly or biweekly to the study survey center, 
where trained interviewers attempted to call potential subjects within 21 days of receiving their information (so that their care experience would still be recent). Contacted patients willing to be surveyed were first screened to verify that they had received the medication from a physician in a participating clinic and that it was intended to treat depression. Subjects then needed to have a score of at least 7 on the 9-item Patient Health Questionnaire (PHQ-9) assessment for depression severity (since the gap of up to 30 days between fill and contact may have already resulted in improvement) and to consent to completing the survey (scores of 5-9 $=$ mild depression, $10-14=$ moderate depression, $15-19=$ moderately severe depression, and $>19=$ severe depression). ${ }^{19,20}$

\section{Survey}

The full survey collected information about demographic characteristics, depression history, quality of life, productivity, and the type of care the patient had received, as well as their satisfaction with that care. ${ }^{21}$ The care process questions were adapted from the Patient Assessment of Chronic Illness Care to focus on depression care and to include questions specific to the evidence-based care processes for depression. ${ }^{22,23}$ Six of these questions addressed SDM aspects of care (see Table 1), as suggested by the definition by the Informed Medical Decision Foundation. A composite score was

Table 1. Shared Decision-Making Questions ( $N=1168$ Respondents )

\begin{tabular}{lc}
\hline Questions & Yes Responses (\%) \\
\hline During the past 6 months of & \\
depression treatment, were you: & 37.0 \\
1. Asked for your ideas and & \\
preferences regarding your & \\
depression treatment? & \\
2. Asked about your concerns and & \\
questions with regard to & 75.2 \\
depression treatment? & \\
3. Sure that your doctor considered & \\
your values and goals when \\
recommending treatment? \\
4. Provided with a treatment plan \\
you could do in your daily life? \\
$\begin{array}{l}\text { 5. Asked about any problems or side } \\
\text { effects from your treatments? }\end{array}$ \\
$\begin{array}{l}\text { 6. Asked whether you preferred } \\
\text { medications or counseling? }\end{array}$ \\
\begin{tabular}{l} 
Composite (standard deviation) \\
\hline
\end{tabular}
\end{tabular}

created as the proportion of the 6 components that patients reported receiving, so it ranged from $0 \%$ to $100 \%$.

\section{Analysis}

Internal consistency of the SDM composite was assessed using the Kuder-Richardson 20 statistic, whereas bivariate relationships among the constituent items were assessed using the Kendall $\tau$-b statistic $(\tau)$. These statistics are conceptually similar to the Cronbach $\alpha$ and Pearson correlation coefficient but appropriate for use with binary variables. The 6 items had a standardized internal consistency of 0.78 per the Kuder-Richardson 20 test, with concordance between individual items ranging from 0.27 to 0.54 per the Kendall $\tau$ statistic.

A general linear mixed model (SAS PROC MIXED) estimated the intraclass correlation coefficient in SDM at zero across the participating clinics at which the patients had received care. A positive intraclass correlation coefficient would have indicated nonindependence in patient observations, thereby violating a key assumption of a general linear model (GLM).

In light of no systematic variation in SDM by clinic, GLMs (SAS PROC) estimated the significance of relationships between patient characteristics and SDM. Relationships between clinic characteristics and SDM are presented descriptively since no inferential tests involving clinic characteristics were performed.

Univariate GLMs predicted SDM scores from patient characteristics to quantify significant differences in SDM across patient subgroups. Before estimating a multivariate GLM, $\chi^{2}$ statistics assessed bivariate relationships among patient characteristics. When collinearity was observed among sets of characteristics, one was selected to represent the set, depending on which would best capture the conceptual relationships within the empirically related set. Household income was retained as a proxy for socioeconomic status, whereas marital, education, and employment statuses were dropped. Functional health status was retained rather than the depression-specific PHQ-9 score. Insurance type was dropped because of its collinearity with age and household income.

Two multivariate GLMs were estimated from this reduced set of patient characteristics. The first estimated the main effects of all the retained set of patient characteristics. The second estimated all 
main and 2-way interaction effects, retaining only the main effects and any significant 2-way interactions. All analyses were conducted using SAS software version 9.2 (SAS Inc., Cary, NC). This study was reviewed, approved, and monitored by the HealthPartners Institutional Review Board.

\section{Results}

The 88 primary care clinics with data included in these analyses belong to 23 different medical groups (a medical group is a set of clinic sites with common ownership and management). Nine of these groups had 1 to 4 total primary care clinic sites, 4 had 5 to 10 , and 10 had $>10$. Of the clinics, 22 had 1 to 4 adult primary care physicians for these patients, 48 had 5 to 10 , and 17 had $>10$. Most (82\%) also had at least one advanced practice clinician (nurse practitioner or physician assistant). Of the 88 clinics, 7 were in large outstate cities (Duluth and Rochester), 35 were in more rural areas, and 46 were in the greater metropolitan area of Minneapolis and St. Paul.

The 1168 patients who completed surveys before their clinic received training for the new care model are described in Table 2. Eligible participants included 7155 people who were identified by the health plans as receiving antidepressant medications from the 88 clinics and who could be contacted within 21 days of that fill. Of these, 1994 (27.9\%) refused screening; 420 (5.9\%) were unable to participate because of language, health, or mental status problems; and 3561 (49.8\%) were excluded because of denying they had received an antidepressant $(\mathrm{n}=110,1.5 \%)$, the prescription was not from a participating clinic $(\mathrm{m}=247$, $3.5 \%)$, the prescription was not for depression ( $\mathrm{n}=$ 1481, 20.7\%), or their PHQ-9 score was $<7$ ( $\mathrm{n}=$ $1723,24.1 \%)$. A final 12 (0.2\%) refused consent. The 1168 enrolled usual care patients were not substantively different from the original sampling frame with respect to age (sampling frame mean age: 45.3 years, enrolled mean age: 44.2 years); sex (sampling frame: $69.5 \%$ female, enrolled: $72.9 \%$ female); clinic location (sampling frame: $65.3 \%$ urban, enrolled: $61.1 \%$ urban); or insurance type (sampling frame: $67.9 \%$ commercially insured, enrolled: $67.8 \%$ commercially insured).

Table 2 shows the overall group responses to the SDM questions, with $34 \%$ to $75 \%$ responding yes to each question. The average composite score on a scale of 0 to 100 was 50.7 with a standard deviation of 32.8. Being sure that the physician considered their preferences and goals was reported most frequently by patients.

In Table 3, patient, clinic, and group characteristics are compared in terms of their composite SDM scores. There were several statistically significant differences when SDM was compared separately across these characteristics. SDM scores were lower among those who were older, had been receiving treatment for at least 6 weeks, were not seeking additional treatment for depression, reported poorer health status, had less education, were not employed, or were insured through Medicare.

Table 4 summarizes the results of the multivariate associations of selected patient characteristics with SDM. SDM scores were lower among older age groups, with those 50 to 64 years old $(P=.001)$ and $\geq 65$ years old $(P<.001)$ reporting significantly lower scores than those 35 to 49 years old. Patients who had been receiving treatment for at least 6 weeks reported lower SDM than those who had been receiving treatment for less time $(P<$ .001). Poverty $(P=.03)$ and poor health $(P<.001)$ also were associated with lower SDM scores. All these differences persisted in the second multivariate GLM, with the additional finding that men in relatively poor health reported less SDM than did those in good health.

Finally, scores for patients' self-reported rating of the quality of depression care they had received at their primary care clinic over the past month were positively correlated with their SDM scores (Pearson $r=0.48 ; P<.001$ ).

\section{Discussion}

We found few differences in patient-reported receipt of SDM by organizational characteristics and more by patient characteristics. The largest difference was a fairly marked and steady decrease in SDM reports from patients who were older. Older adults (those $\geq 65$ years old) reported only half as much SDM as young adults (ages 18-34 years), with a smaller decrease among those aged 50 to 64 years. This is consistent with lower overall recognition and treatment rates for depression among older adults and probably represents some combination of patient and physician characteristics. ${ }^{24}$

On the patient side, Proctor et $\mathrm{a}^{25}$ found that older adults often placed a lower priority on care 
Table 2. Personal, Clinic, and Group Characteristics of 1168 Enrolled Patients

\begin{tabular}{|c|c|c|}
\hline Characteristics & No. & $\%$ \\
\hline \multicolumn{3}{|l|}{ Patients } \\
\hline \multicolumn{3}{|l|}{ Sex } \\
\hline Female & 851 & 72.9 \\
\hline Male & 317 & 27.1 \\
\hline \multicolumn{3}{|l|}{ Age (years) } \\
\hline $18-34$ & 344 & 29.5 \\
\hline $35-49$ & 391 & 33.5 \\
\hline $50-64$ & 347 & 39.7 \\
\hline$\geq 65$ & 86 & 7.4 \\
\hline \multicolumn{3}{|l|}{ Ethnicity/race } \\
\hline Non-Hispanic white & 1022 & 87.5 \\
\hline Hispanic, any race & 43 & 3.7 \\
\hline Non-Hispanic, nonwhite & 103 & 8.8 \\
\hline \multicolumn{3}{|l|}{ Treated for this depression } \\
\hline $0-5$ weeks & 543 & 46.5 \\
\hline$\geq 6$ weeks & 607 & 52.0 \\
\hline \multicolumn{3}{|c|}{$\begin{array}{l}\text { Other depression treatment in past } 6 \\
\text { months }\end{array}$} \\
\hline Individual counseling & 299 & 25.6 \\
\hline Group therapy & 45 & 3.8 \\
\hline Psychiatry & 69 & 5.9 \\
\hline Other treatment & 41 & 3.5 \\
\hline Any treatment & 376 & 32.2 \\
\hline \multicolumn{3}{|l|}{ General health } \\
\hline Excellent/very good & 383 & 32.8 \\
\hline Good & 437 & 37.4 \\
\hline Fair/poor & 348 & 29.8 \\
\hline \multicolumn{3}{|l|}{ PHQ-9 score } \\
\hline $7-9$ & 367 & 31.4 \\
\hline $10-14$ & 446 & 38.2 \\
\hline $15-19$ & 244 & 20.9 \\
\hline$\geq 20$ & 111 & 9.5 \\
\hline \multicolumn{3}{|l|}{ Education } \\
\hline High school or less & 355 & 30.4 \\
\hline Some college, trade school & 468 & 40.1 \\
\hline College degree or more & 345 & 29.5 \\
\hline \multicolumn{3}{|l|}{ Marital status } \\
\hline Married & 569 & 48.7 \\
\hline Unmarried couple & 101 & 8.6 \\
\hline Divorced/separated/widowed & 268 & 22.9 \\
\hline Never married & 229 & 19.6 \\
\hline \multicolumn{3}{|l|}{ Employment } \\
\hline Employed for wages & 696 & 59.6 \\
\hline Self-employed & 69 & 5.9 \\
\hline Unemployed & 117 & 10.0 \\
\hline Homemaker & 45 & 3.9 \\
\hline Student & 47 & 4.0 \\
\hline Retired & 82 & 7.0 \\
\hline Unable to work & 112 & 9.6 \\
\hline
\end{tabular}

Continued
Table 2. Continued

\begin{tabular}{lrr}
\hline Characteristics & No. & $\%$ \\
\hline Household income & & \\
$\quad$ Below poverty threshold & 205 & 17.5 \\
$\quad$ Between threshold and 2× & 166 & 14.2 \\
$\quad$ threshold & & \\
$\quad$ More than 2× threshold & 749 & 64.1 \\
$\quad$ Declined to answer & 48 & 4.1 \\
Insurance type & & \\
Commercial & 792 & 67.8 \\
State programs* & 270 & 23.1 \\
Medicare & 61 & 5.2 \\
Other & 34 & 2.9
\end{tabular}

Clinics

Adult PCPs in clinic (n)

$\begin{array}{lll}1-4 & 159 & 13.6\end{array}$

$\begin{array}{lll}5-10 & 510 & 43.7\end{array}$

$\begin{array}{lll}\geq 11 & 497 & 42.6\end{array}$

NPs/PAs in clinic (n)

$\begin{array}{lll}0 & 124 & 10.6\end{array}$

$\geq 1 \quad 1044 \quad 89.4$

Clinic location

$\begin{array}{lll}\text { Urban } & 714 & 61.1\end{array}$

Rural $\quad 454 \quad 38.9$

Medical groups

Care sites in group (n)

$\begin{array}{lll}1-4 & 274 & 23.5\end{array}$

$\begin{array}{lrr}5-10 & 98 & 8.4\end{array}$

$\begin{array}{lll}\geq 11 & 796 & 68.2\end{array}$

$\begin{array}{lll}\text { Psychiatrists in group (n) } & & \\ 0 & 390 & 33.4\end{array}$

$\geq 1 \quad 778 \quad 66.6$

Mental health therapists in group (n)

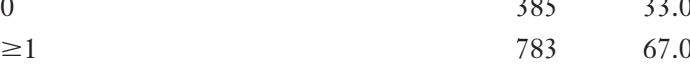

*Medical Assistance, Prepaid Medical Assistance, Minnesota Care, Minnesota Senior Health Options.

$\mathrm{NP}$, nurse practitioner; PA, physician assistant; PCP, primary care physician; PHQ-9, 9-item Patient Health Questionnaire.

for depression compared with physical problems. Callahan et $\mathrm{al}^{26}$ demonstrated many differences between older and younger adults in the content of their physician interactions, but the differences were small and there was no difference in negotiation. Older adults may also be less likely to expect or want SDM behaviors from their providers or have different interactional styles. While we have no information about the characteristics of the treating physicians, Young et $\mathrm{al}^{15}$ found fewer SDM behaviors among older physicians, and older 
Table 3. Bivariate Relationships Between Patient, Clinic, and Group Characteristics and Shared Decision Making

\begin{tabular}{|c|c|c|c|c|}
\hline Characteristics & No. & Mean* & $\mathrm{SD}$ & $P$ Value \\
\hline \multicolumn{5}{|l|}{ Patients } \\
\hline \multicolumn{5}{|l|}{ Sex } \\
\hline Female & 848 & 51.2 & 33.0 & \multirow[t]{2}{*}{.40} \\
\hline Male & 314 & 49.4 & 32.2 & \\
\hline \multicolumn{5}{|l|}{ Age (years) } \\
\hline $18-34$ & 343 & 58.3 & 31.0 & \multirow[t]{2}{*}{.03} \\
\hline $35-49$ & 390 & 53.3 & 32.4 & \\
\hline $50-64$ & 345 & 44.5 & 32.8 & $<.001$ \\
\hline$\geq 65$ & 84 & 32.7 & 31.1 & $<.0001$ \\
\hline \multicolumn{5}{|l|}{ Ethnicity/race } \\
\hline Non-Hispanic white & 1016 & 50.4 & 33.2 & \\
\hline Hispanic, any race & 43 & 45.7 & 30.9 & .36 \\
\hline Non-Hispanic, nonwhite & 103 & 55.8 & 29.4 & .11 \\
\hline \multicolumn{5}{|l|}{ Treated for this depression } \\
\hline $0-5$ weeks & 540 & 56.6 & 29.7 & \multirow[t]{2}{*}{$<.001$} \\
\hline$\geq 6$ weeks & 604 & 45.5 & 34.5 & \\
\hline \multicolumn{5}{|c|}{ Any other depression treatment in past 6 months } \\
\hline No & 788 & 46.0 & 33.1 & \\
\hline Yes & 371 & 60.5 & 30.0 & $<.0001$ \\
\hline \multicolumn{5}{|l|}{ General health } \\
\hline Excellent/very good/good & 815 & 53.9 & 32.1 & \\
\hline Fair/poor & 347 & 43.1 & 33.2 & $<.001$ \\
\hline \multicolumn{5}{|l|}{ PHQ-9 score } \\
\hline $7-9$ & 364 & 51.6 & 32.0 & \multirow[t]{2}{*}{.75} \\
\hline $10-14$ & 444 & 50.8 & 33.5 & \\
\hline $15-19$ & 243 & 49.9 & 32.6 & .71 \\
\hline$\geq 20$ & 111 & 49.1 & 33.2 & .62 \\
\hline \multicolumn{5}{|l|}{ Education } \\
\hline High school or less & 354 & 47.2 & 31.6 & .02 \\
\hline Some college, trade school & 466 & 51.5 & 32.7 & \multirow[t]{2}{*}{.46} \\
\hline College degree or more & 342 & 53.2 & 34.0 & \\
\hline \multicolumn{5}{|l|}{ Marital status } \\
\hline Coupled & 666 & 51.6 & 32.5 & \\
\hline Not coupled & 495 & 49.4 & 33.2 & .26 \\
\hline \multicolumn{5}{|l|}{ Employment } \\
\hline Employed & 761 & 52.9 & 32.4 & \\
\hline Not employed & 401 & 46.5 & 33.2 & .001 \\
\hline \multicolumn{5}{|l|}{ Household income } \\
\hline Below $2 \times$ poverty threshold & 389 & 49.1 & 32.5 & \\
\hline Above $2 \times$ poverty threshold & 744 & 52.0 & 33.1 & .15 \\
\hline \multicolumn{5}{|l|}{ Insurance type } \\
\hline Commercial & 787 & 52.2 & 33.1 & \\
\hline State programs & 270 & 52.1 & 31.8 & .95 \\
\hline Medicare & 60 & 29.4 & 27.8 & $<.0001$ \\
\hline Other & 34 & 42.6 & 30.2 & .09 \\
\hline
\end{tabular}


Table 3. Continued

\begin{tabular}{|c|c|c|c|c|}
\hline Characteristics & No. & Mean* & $\mathrm{SD}$ & $P$ Value \\
\hline \multicolumn{5}{|l|}{ Clinics } \\
\hline \multicolumn{5}{|c|}{ Adult PCPs in clinic (n) } \\
\hline $1-4$ & 159 & 49.5 & 32.3 & \\
\hline $5-10$ & 506 & 51.6 & 32.4 & \\
\hline$\geq 11$ & 495 & 50.0 & 33.5 & \\
\hline \multicolumn{5}{|c|}{ NPs/PAs in clinic (n) } \\
\hline 0 & 122 & 50.3 & 31.3 & \\
\hline$\geq 1$ & 1038 & 50.7 & 33.0 & \\
\hline \multicolumn{5}{|l|}{ Clinic location } \\
\hline Urban & 709 & 50.1 & 32.8 & \\
\hline Nonurban & 453 & 51.6 & 32.8 & \\
\hline \multicolumn{5}{|l|}{ Medical groups } \\
\hline \multicolumn{5}{|c|}{ Care sites in group (n) } \\
\hline 1 to 4 & 273 & 54.1 & 32.2 & \\
\hline 5 to 10 & 98 & 44.4 & 30.5 & \\
\hline$\geq 11$ & 791 & 50.3 & 33.2 & \\
\hline \multicolumn{5}{|c|}{ Psychiatrists in group (n) } \\
\hline 0 & 389 & 50.3 & 31.6 & \\
\hline$\geq 1$ & 773 & 50.9 & 33.4 & \\
\hline \multicolumn{5}{|c|}{ Mental health therapists in group (n) } \\
\hline 0 & 384 & 51.4 & 31.6 & \\
\hline$\geq 1$ & 778 & 50.3 & 33.4 & \\
\hline
\end{tabular}

${ }^{*}$ Mean percentage of 6 items answered yes.

NP, nurse practitioner; PA, physician assistant; PCP, primary care physician; PHQ-9, 9-item Patient Health Questionnaire; SD, standard deviation.

patients tend to be cared for by older physicians. Wittink et $\mathrm{al}^{27}$ interviewed 15 physicians who felt that older patients tend to attribute depression to nonmedical causes, so the physician needed to first convince them of the medical model, perhaps reducing the time and inclination to use SDM as well. Finally, Chapman et $\mathrm{al}^{28}$ concluded from standardized measures of patient-centered communications for patients with depression that physicians' personality characteristics explained $4 \%$ to $7 \%$ of the variance and physician characteristics, training, and patient presentation accounted for another $4 \%$ to $7 \%$.

Those who had been receiving treatment for some time (many for years) also reported less SDM, a finding that was unrelated to the severity of their depression symptoms $(P=.65)$. Perhaps this reflects either the greater opportunity for a poor experience over a longer course of treatment or that patient choices and preferences may be more actively solicited as a new treatment plan is being established than during later phases when decisions about treatment are already in effect. It is not surprising that those reporting receiving other treat- ments were more likely to experience SDM conversations, since changes in treatment would be more likely to stimulate such a discussion.

Several exploratory findings (based on a significant interaction in the multivariate analysis) deserve attention. One is that poorer health was associated with significantly less SDM among men than women. Sherbourne et $\mathrm{a}^{29}$ have shown that men are less likely than women to receive medical care for depression, but we found no sex difference in the use of SDM except among those in fair/poor health.

Although there is extensive literature on related topics such as SDM and physician-patient communication, there are few studies of reports of SDM from depressed patients with which to compare our results. The analysis of audiotaped encounters at a first visit for depression treatment by Young et $\mathrm{al}^{15}$ found mean scores for SDM of only $23 \%$ versus our patient report of about $50 \%$, perhaps reflecting differences in the measures used or in the degree to which patient experiences are shaped by multiple versus a single encounter. It may also represent differences between patients' perceptions and/or 
Table 4. Multivariate Model-Predicted Differences in Shared Decision Making Among Selected Patient Subgroups Relative to a Reference Group

\begin{tabular}{|c|c|c|c|c|}
\hline \multirow[b]{2}{*}{ Characteristics } & \multicolumn{2}{|c|}{ Only Main Effects } & \multicolumn{2}{|c|}{ Main Effects Plus Interaction } \\
\hline & Difference & $P$ Value* & Difference & $P$ Value* \\
\hline \multicolumn{5}{|l|}{ Sex } \\
\hline Female & Ref & & Ref & \\
\hline Male & -2.2 & .29 & N/A & \\
\hline \multicolumn{5}{|l|}{ Age (years) } \\
\hline $18-34$ & 4.2 & .08 & 4.1 & .08 \\
\hline $35-49$ & Ref & & Ref & \\
\hline $50-64$ & -7.6 & .001 & -7.8 & $<.001$ \\
\hline$\geq 65$ & -16.0 & $<.001$ & -15.9 & $<.001$ \\
\hline \multicolumn{5}{|l|}{ Ethnicity/race } \\
\hline Non-Hispanic white & Ref & & Ref & \\
\hline Hispanic, any race & -5.0 & .31 & N/A & \\
\hline Non-Hispanic, nonwhite & 4.2 & .21 & N/A & \\
\hline \multicolumn{5}{|l|}{ Treated for this depression } \\
\hline $0-5$ weeks & Ref & & Ref & \\
\hline$\geq 6$ weeks & -11.0 & $<.001$ & -11.2 & $<.001$ \\
\hline \multicolumn{5}{|c|}{ Any other depression treatment in past 6 months } \\
\hline No & Ref & & Ref & \\
\hline Yes & 14.0 & $<.0001$ & 14.0 & $<.001$ \\
\hline \multicolumn{5}{|l|}{ General health } \\
\hline Excellent/very good/good & Ref & & Ref & \\
\hline Fair/poor & -7.5 & $<.001$ & N/A & \\
\hline \multicolumn{5}{|l|}{ Household income } \\
\hline Below $2 \times$ poverty threshold & -4.2 & .04 & -3.9 & .06 \\
\hline Above $2 \times$ threshold & Ref & & Ref & \\
\hline \multicolumn{5}{|l|}{ General health by sex } \\
\hline \multicolumn{5}{|l|}{ Female } \\
\hline Excellent/very good/good & & & Ref & \\
\hline Fair/poor & & & -4.7 & .05 \\
\hline \multicolumn{5}{|l|}{ Male } \\
\hline Excellent/very good/good & & & 0.8 & .74 \\
\hline Fair/poor & & & -10.0 & $<.03$ \\
\hline
\end{tabular}

${ }^{*} P$ value compares predicted difference to reference category.

what they are willing to report compared with scoring by objective observers. In an analysis of videotapes of 385 primary care visits with older adults, of whom $50 \%$ were depressed, Tai-Seale and colleagues $^{30}$ established that the average amount of time devoted to discussing mental health problems was 2 minutes, including discussion of treatment options, leaving little time for SDM. Future research to understand the links between patient experiences of SDM and the observable contents of primary care visits is needed.

The important question is whether more SDM might lead to improved patient outcomes, but the only such study by Clever et $\mathrm{a}^{13}$ found that patient involvement in decision making was associated with both increases in guideline-concordant care and a higher remission rate. Swanson et $\mathrm{al}^{31}$ found that SDM was positively associated with satisfaction in a study of 1317 patients with depression in managed care settings. Stein et $\mathrm{al}^{32}$ tested a computerized tool for medication SDM in adults insured by Medicaid who were receiving psychotropic medication from community mental health centers and found no effect on medication adherence, but they did not also measure SDM behaviors. A Cochrane systematic review of the effects of SDM interventions by Duncan et $\mathrm{al}^{33}$ concluded that " $\mathrm{no}$ firm conclusions can be drawn at present about the effects of [SDM] 
interventions for people with mental health conditions. There is no evidence of harm, but there is need for further research in this area."

This study was limited to a single state, to patients with active depression that might affect their ability to recall or judge the care they receive, and to patients being actively treated with antidepressant medications in clinics that had volunteered and therefore probably had a greater interest in improving depression care. It is possible that SDM in these clinics was not typical, but we had no way to measure that. Therefore, differences in scores may not reflect actual differences in care and may have been affected by differences among patients in their expectations of and preferences for SDM. Nevertheless, this study suggests that there is a large degree of variation in the extent to which depressed patients report experiencing SDM and that elderly patients and those who remain in treatment over extended periods of time are less likely to report participating in SDM. Introduction of the collaborative care model for depression that has been demonstrated to improve outcomes (and was the focus for the initiative for which these clinics volunteered) seems likely to result in improved SDM. Data now being analyzed can address this. Further studies will still be needed to determine whether providing greater SDM in depression care results in better patient outcomes.

This study would not have been possible without the extensive cooperation of 6 health plans and the Minnesota Department of Human Services in identifying subjects, all 88 primary care clinics, the Institute for Clinical Systems Improvement, and the Data Collection Center at HealthPartners Institute for Education and Research.

\section{References}

1. Institute of Medicine. Crossing the quality chasm: a new health system for the 21 st century. Washington, DC: National Academies Press; 2001.

2. Epperly T. The patient-centred medical home in the USA. J Eval Clin Pract 2011;17:373-5.

3. Peikes D, Zutshi A, Genevro JL, Parchman ML, Meyers DS. Early evaluations of the medical home: building on a promising start. Am J Manag Care 2012;18:105-16.

4. Barry MJ, Edgman-Levitan S. Shared decision making-pinnacle of patient-centered care. $\mathrm{N}$ Engl J Med 2012;366:780-1.

5. Lin GA, Dudley RA. Patient-centered care: what is the best measuring stick? Arch Intern Med 2009;169: 1551-3.
6. Kryworuchko J, Stacey D, Bennett C, Graham ID. Appraisal of primary outcome measures used in trials of patient decision support. Patient Educ Couns 2008;73:497-503.

7. Saba GW, Wong ST, Schillinger D, et al. Shared decision making and the experience of partnership in primary care. Ann Fam Med 2006;4:54-62.

8. Towle A, Godolphin W, Grams G, Lamarre A. Putting informed and shared decision making into practice. Health Expect 2006;9:321-32.

9. Hanson JL. Shared decision making: have we missed the obvious? Arch Intern Med 2008;168:1368-70.

10. Gilbody S, Bower P, Fletcher J, Richards D, Sutton AJ. Collaborative care for depression: a cumulative meta-analysis and review of longer-term outcomes. Arch Intern Med 2006;166:2314-21.

11. Williams JW Jr, Gerrity M, Holsinger T, Dobscha S, Gaynes B, Dietrich A. Systematic review of multifaceted interventions to improve depression care. Gen Hosp Psychiatry 2007;29:91-116.

12. Christensen H, Griffiths KM, Gulliver A, Clack D, Kljakovic M, Wells L. Models in the delivery of depression care: a systematic review of randomised and controlled intervention trials. BMC Fam Pract 2008;9:25.

13. Clever SL, Ford DE, Rubenstein LV, et al. Primary care patients' involvement in decision-making is associated with improvement in depression. Med Care 2006;44:398-405.

14. Loh A, Simon D, Wills CE, Kriston L, Niebling W, Harter M. The effects of a shared decision-making intervention in primary care of depression: a clusterrandomized controlled trial. Patient Educ Couns 2007;67:324-32.

15. Young HN, Bell RA, Epstein RM, Feldman MD, Kravitz RL. Physicians' shared decision-making behaviors in depression care. Arch Intern Med 2008; 168:1404-8.

16. Solberg LI, Glasgow RE, Unützer J, et al. Partnership research: a practical trial design for evaluation of a natural experiment to improve depression care. Med Care 2010;48:576-82.

17. Korsen N, Cartwright C. Developing and disseminating a model to improve depression care in primary care practices. J Clin Outcomes Manage 2006; 13:506-11.

18. Unutzer J, Katon W, Callahan CM, et al. Collaborative care management of late-life depression in the primary care setting: a randomized controlled trial. JAMA 2002;288:2836-45.

19. Kroenke K, Spitzer RL. The PHQ-9: a new depression and diagnostic severity measure. Psychiatric Ann 2002;32:509-21.

20. Kroenke K, Spitzer RL, Williams JB. The PHQ-9: validity of a brief depression severity measure. J Gen Intern Med 2001;16:606-13. 
21. Mattke S, Balakrishnan A, Bergamo G, Newberry SJ. A review of methods to measure health-related productivity loss. Am J Manag Care 2007;13:211-7.

22. Glasgow RE, Wagner EH, Schaefer J, Mahoney LD, Reid RJ, Greene SM. Development and validation of the Patient Assessment of Chronic Illness Care (PACIC). Med Care 2005;43:436-44.

23. Glasgow RE, Whitesides H, Nelson CC, King DK. Use of the Patient Assessment of Chronic Illness Care (PACIC) with diabetic patients: relationship to patient characteristics, receipt of care, and self-management Diabetes Care 2005;28:2655-61.

24. Shim RS, Baltrus P, Ye J, Rust G. Prevalence, treatment, and control of depressive symptoms in the united states: results from the national health and nutrition examination survey (NHANES), 20052008. J Am Board Fam Med 2011;24:33-8.

25. Proctor EK, Hasche L, Morrow-Howell N, Shumway M, Snell G. Perceptions about competing psychosocial problems and treatment priorities among older adults with depression. Psychiatr Serv 2008;59: $670-5$.

26. Callahan EJ, Stange KC, Zyzanski SJ, Goodwin MA, Flocke SA, Bertakis KD. Physician-elder interaction in community family practice. J Am Board Fam Pract 2004;17:19-25.

27. Wittink MN, Givens JL, Knott KA, Coyne JC, Barg FK. Negotiating depression treatment with older adults: primary care providers' perspectives. J Ment Health 2011;20:429-37.
28. Chapman BP, Duberstein PR, Epstein RM, Fiscella K, Kravitz RL. Patient-centered communication during primary care visits for depressive symptoms: what is the role of physician personality? Med Care 2008;46:806-12.

29. Sherbourne CD, Weiss R, Duan N, Bird CE, Wells KB. Do the effects of quality improvement for depression care differ for men and women? Results of a group-level randomized controlled trial. Med Care 2004;42:1186-93.

30. Tai-Seale M, Foo PK, Stults CD. Patients with mental health needs are engaged in asking questions, but physicians' responses vary. Health Aff (Millwood) 2013;32:259-67.

31. Swanson KA, Bastani R, Rubenstein LV, Meredith LS, Ford DE. Effect of mental health care and shared decision making on patient satisfaction in a community sample of patients with depression. Med Care Res Rev 2007;64:416-30.

32. Stein BD, Kogan JN, Mihalyo MJ, et al. Use of a computerized medication shared decision making tool in community mental health settings: impact on psychotropic medication adherence. Community Ment Health J 2013;49:185-92.

33. Duncan E, Best C, Hagen S. Shared decision making interventions for people with mental health conditions. Cochrane Database Syst Rev 2010;(1): CD007297. 